\title{
An Investigation on the Human Thermal Comfort from a Glass Window
}

\author{
Nopparat Khamporn $^{a}$ and Somsak Chaiyapinunt ${ }^{b}$ \\ Department of Mechanical Engineering, Faculty of Engineering, Chulalongkorn University, Phayathai Road, \\ Bangkok 10330, Thailand \\ E-mail: anopparat.k@student.chula.ac.th, bsomsak.ch@chula.ac.th (Corresponding author)
}

\begin{abstract}
The effect of the glass window on the thermal comfort of a person sitting near the glass window is investigated by performing the experiment in a test room. A clear glass window and a tinted glass window are chosen to be the test windows in this study. The index chosen to describe the thermal comfort is the predicted percentage of dissatisfied (PPD). The important parameter for evaluating the human thermal comfort condition is the mean radiant temperature. The mathematical model for predicting the mean radiant temperature is presented. The predicted mean radiant temperature and the mean radiant temperature evaluated from the operative temperature are compared. The agreement is good. It is found that the mean radiant temperature, the predicted mean vote (PMV) and the PPD are all dependent on the transmitted solar radiation and the surface temperature of the glass window. Higher value of the mean radiant temperature yields higher value of the PMV and the PPD. The room with a clear glass window installed has a high thermal discomfort condition which is mainly come from the solar radiation. The amount of the thermal discomfort is directly varied with the amount of the transmitted solar radiation. For a high transmittance glass window, the thermal discomfort due to solar radiation is greater than the thermal discomfort due to surface temperature. For a low transmittance (high absorptance) glass window, the thermal discomfort due to surface temperature becomes important when compared to the thermal discomfort in the part of solar radiation.
\end{abstract}

Keywords: Glass window, thermal comfort, mean radiant temperature, operative temperature, predicted percentage of dissatisfied (PPD).

ENGINEERING JOURNAL Volume 18 Issue 1

Received 22 April 2013

Accepted 9 July 2013

Published 14 January 2014

Online at http://www.engj.org/

DOI:10.4186/ej.2014.18.1.25 


\section{Introduction}

Large commercial buildings usually have their building envelope made of glass window. These glass windows shall receive plenty of heat gain into building from the incident solar radiation especially when the building is located in a tropic zone near the equator. The large air conditioning system is usually needed to get rid of the heat gain from solar radiation. Besides the heat gain through the glass window, the glass window also has the effect on the person who sits nearby in term of thermal comfort. Thermal comfort is defined as the condition of mind that expressed satisfaction with the thermal environment (ISO 7730 [1] and ASHRAE Standard 55 [2]). The important parameters which commonly used to describe the thermal comfort condition are the mean radiant temperature, the predicted mean vote (PMV) and the predicted percentage of dissatisfied (PPD). Fanger [3] has related PMV value to the parameters that affects the thermal comfort. Rizzo et al. [4] have developed the algolithms for calculating the mean projected area factors of the seated and standing persons. Athienitis and Haghighat [5] have performed the experimental and numerical study of the effects of solar radiation on the indoor environment. They presented the effects of both transmitted direct solar radiation and transmitted diffuse solar radiation on the human thermal comfort in terms of globe temperature. Cannistraro et al. [6] developed the view factors between human body and rectangular surfaces in parallelepiped environments in the form of polynomial equation. La Gennusa et al. [7] have developed the mathematical model to determine the mean radiant temperature of a subject exposed to solar radiation. Sullivan [8] and Lyons et al. [9] have developed the relation to calculate the PMV that accounted for the solar radiation effect. Chaiyapinunt et al. [10] have done the performance rating on the glass windows and glass windows with films in term of thermal comfort and heat transmission. They have shown that the optical properties of the glass windows and glass windows with films have significantly impacted on the thermal performance both in term of thermal comfort and heat transmission. The results of the study (thermal performance) are all based on one chosen local design condition. La Gennusa et al. [11] have developed a model to manage and evaluate the effect of the solar radiation for indoor thermal comfort. Ibrahim et al. [12] have done the study on the effect of the radiant temperature on thermal comfort in a room without the glass window. Singh et al. [13] have studied different glazing systems and their impact on the thermal comfort based on the certain Indian local weather conditions. Chan and Mak [14] have investigated the thermal comfort levels in a room with solar radiation. Chaiyapinunt and Khamporn [15] have developed the parameters and the relationships for selecting a proper glass window applied with film as building envelope for buildings located in a hot climate based on the thermal performance in term of thermal comfort. Dong et al. [16] have studied on the effect of the variation of the mean radiant temperature on the energy consumption of the office which the predicted mean vote was controlled. Hwang and Shu [17] have studied on the effect of different kinds of the glass building envelope on thermal comfort and also studied the energy saving potential by using the thermal comfort index as the control strategy instead of the thermostat. Francesca et al. [18] and Dell'Isola et al. [19] have done the assessment on the accuracy and uncertainty of the measurement of the thermal comfort by using the predicted mean vote. Most of the works mentioned earlier were based on the simulation results from the mathematical model. The experimental study that has been performed was to evaluate the human thermal comfort by using the globe temperature (measured by the globe thermometer). In this study, the effect of the glass window on the human thermal comfort is investigated in detail by performing the experiment using two types of glass window. The operative temperature transducer is also used to measure the operative temperature of the test room with the glass window installed. The mean radiant temperature which is one of the important parameters will be determined from the mathematical model using the related measured data from the experiment. The mean radiant temperature will also be evaluated from the measured value of the operative temperature from the operative temperature transducer.

\section{Thermal Comfort Index}

The indices that commonly used to describe the human thermal comfort condition are the predicted mean vote (PMV) and the predicted percentage of dissatisfied (PPD). The expression for PMV and PPD can be written according to ISO 7730 [1] and Fanger [3] as 


$$
\begin{gathered}
P M V=\left(0.303 e^{-0.036 \cdot M}+0.028\right) \cdot\left[M(1-\eta)-3.05 \times 10^{-3} \cdot\left(5733-6.99 \cdot M(1-\eta)-P_{a}\right)\right. \\
-0.42 \cdot(M(1-\eta)-58.15)-1.7 \times 10^{-5} \cdot M \cdot\left(5867-P_{a}\right)-0.0014 \cdot M \cdot\left(34-T_{a}\right) \\
\left.-3.96 \times 10^{-8} f_{c l} \cdot\left(\left(T_{c l}+273\right)^{4}-\left(T_{m r t}+273\right)^{4}\right)-f_{c l} \cdot h_{c}\left(T_{c l}-T_{a}\right)\right] \\
P P D=100-95 \cdot e^{-\left(0.03353 P M V^{4}+0.2179 P M V^{2}\right)}
\end{gathered}
$$

where $\quad M=$ metabolic rate per unit body, $\left(\mathrm{W} / \mathrm{m}^{2}\right) ; P_{a}=$ vapor partial pressure, $(\mathrm{Pa}) ; f_{c l}=$ clothing area factor; $T_{m r t}=$ mean radiant temperature, $\left({ }^{\circ} \mathrm{C}\right) ; T_{a}=$ air temperature, $\left({ }^{\circ} \mathrm{C}\right) ; T_{c l}=$ clothing surface temperature, $\left({ }^{\circ} \mathrm{C}\right) ; h_{c}=$ convective heat transfer coefficient, $\left(W /\left(m^{2}-K\right)\right) ; \eta=$ mechanical efficiency.

The clothing surface temperature can be evaluated by an iteration process from the following expressions

$$
\begin{gathered}
T_{c l}=35.7-0.028 M(1-\eta)-I_{c l}\left\{3.96 \times 10^{-8} \cdot f_{c l} \cdot\left[\left(T_{c l}+273\right)^{4}-\left(T_{m r t}+273\right)^{4}\right]+f_{c l} \cdot h_{c} \cdot\left(T_{c l}-T_{a}\right)\right\} \\
h_{c}= \begin{cases}2.38\left(T_{c l}-T_{a}\right)^{0.25} & \text { for } \left.2.38\left(T_{c l}-T_{a}\right)^{0.25}\right\rangle 12.1 \sqrt{v_{a r}} \\
12.1 \sqrt{v_{a r}} & \text { for } 2.38\left(T_{c l}-T_{a}\right)^{0.25}\left\langle 12.1 \sqrt{v_{a r}}\right.\end{cases} \\
f_{c l}=\left\{\begin{array}{lll}
1.00+1.290 I_{c l} & \text { for } I_{c l} \leq 0.078 & \left(m^{2}-K\right) / W \\
1.05+0.645 I_{c l} & \text { for } I_{c l}>0.078 & \left(m^{2}-K\right) / W
\end{array}\right.
\end{gathered}
$$

where $v_{a r}=$ relative air velocity (the air velocity relative to the occupant, including body movements), $(m / s) ; I_{c l}=$ clothing insulation, $\left(\left(m^{2}-K\right) / W\right)$.

Chaiyapinunt et al. [10] have shown that the PPD value for the person who sits near the glass window can be classified as the PPD due to surface temperature and the PPD due to solar radiation. This relationship can be written as

$$
\operatorname{PPD}(\text { total })=\operatorname{PPD}(\text { surface temperature })+\operatorname{PPD}(\text { solar radiation })
$$

where $\operatorname{PPD}($ total $)=$ PPD that accounted for the effect of solar radiation and the effect of surface temperature; PPD(surface temperature) = PPD that accounted for the effect of surface temperature.; PPD $($ solar radiation $)=$ PPD that accounted for the effect of solar radiation.

The mean radiant temperature of an enclosure, which is defined as the uniform temperature of an imaginary black enclosure which would result in the same heat loss by radiation from the person as the actual enclosure, is one of the important parameters needed to use for evaluating the value of the PMV in Eq. (1). Therefore, the mean radiant temperature of the enclosure can also be divided into the mean radiant temperature that is not accounted for the effect of solar radiation that strike on the person who sits near the glass window (accounted only for the effect of the glass surface temperature) and the mean radiant temperature that accounted for the effect of surface temperature and solar radiation. The expression for both kinds of the mean radiant temperature can be written as

$$
\begin{gathered}
T_{t m r t}=\left[\left(t_{s 1}+273\right)^{4} \cdot F_{p-1}+\left(t_{s 2}+273\right)^{4} \cdot F_{p-2}+\ldots \ldots \ldots+\left(t_{s n}+273\right)^{4} \cdot F_{p-n}\right]^{0.25}-273 \\
T_{\text {smrt }}=\left[\left(T_{\text {tmrt }}+273\right)^{4}+\frac{a_{p}}{\varepsilon_{p} \sigma}\left(F_{p-\text { win }} I_{\text {trdiff }}+f_{p} I_{\text {trdir }}\right)\right]^{0.25}-273
\end{gathered}
$$

where $\quad T_{t m r t}=$ mean radiant temperature due to surface temperature, $\left({ }^{\circ} \mathrm{C}\right)$;

$T_{\text {smrt }}=$ mean radiant temperature due to surface temperature and solar radiation, $\left({ }^{\circ} \mathrm{C}\right)$;

$t_{s j}=$ surface temperature of the enclosure wall number $j,\left({ }^{\circ} \mathrm{C}\right)$;

$F_{p-i}=$ angle factor between the person and surface $i\left(\sum_{i}^{n} F_{p-i}=1\right)$;

$F_{p-w i n}=$ angle factor between the person and the glass window surface $(=0.312$ when distance

between the person and glass window is $0.2 \mathrm{~m}$ );

$f_{p}=$ projected area factor;

$a_{p}=$ absorptance of the outer surface of the person (standard value $=0.6$ ); 
$\varepsilon_{p}=$ emittance of the outer surface of the person (standard value $\left.=0.97\right)$;

$\sigma=$ Stefan Boltzmann constant, $\left(W /\left(m^{2}-K^{4}\right)\right)$;

$I_{\text {trdir }}=$ transmitted direct solar radiation striking on the person, $\left(\mathrm{W} / \mathrm{m}^{2}\right)$;

$I_{\text {trdiff }}=$ transmitted diffuse solar radiation striking on the person, $\left(\mathrm{W} / \mathrm{m}^{2}\right)$.

The expression for the mean radiant temperature due to surface temperature and solar radiation in Eq. (8) (in the part of solar radiation effect) has been adopted from the relation given by La Gennusa et al.[7].

In this study, the transmitted direct solar radiation that passed through the glass window striking on the person can be obtained from the following relation as

$$
I_{\text {trdir }}=I_{\text {dir }} \cdot T(\theta)
$$

where $I_{\text {trdir }}=$ direct solar radiation that transmitted through the glass window, $\left(W / m^{2}\right)$;

$I_{\text {dir }}=$ measured direct solar radiation incident on the outside glass window surface, $\left(\mathrm{W} / \mathrm{m}^{2}\right)$;

$T(\theta)=$ glass transmittance which dependent on incident angle.

The diffuse solar radiation striking on the person can then be calculated from the following relation as

$$
I_{\text {trdiff }}=I_{\text {diff }} \cdot T_{\text {diff }}
$$

where $I_{\text {trdiff }}=$ diffuse solar radiation that transmitted through the glass window, $\left(W / m^{2}\right)$;

$I_{\text {diff }}=$ measured diffuse solar radiation incident on the outside glass window surface, $\left(\mathrm{W} / \mathrm{m}^{2}\right)$;

$T_{\text {diff }}=$ glass diffuse transmittance (hemisphere transmittance).

$T(\theta)$ and $T_{\text {diff }}$ for the glass window are evaluated by using the relation suggested by Finlayson et al. [20].

The predicted solar radiation that transmitted through the glass window can also be obtained from the following relation as

$$
\begin{gathered}
I_{\text {tran }}=I_{\text {trdir }}+I_{\text {trdiff }} \\
I_{\text {tran }}=I_{\text {dir }} \cdot T(\theta)+I_{\text {diff }} \cdot T_{\text {diff }} \\
I_{\text {dir }}=I_{\text {glob }}-I_{\text {diff }}
\end{gathered}
$$

where $\quad I_{\text {tran }}=$ global solar radiation that transmitted through the glass window, $\left(\mathrm{W} / \mathrm{m}^{2}\right)$;

$I_{g l o b}=$ global solar radiation that incident on the glass window, $\left(\mathrm{W} / \mathrm{m}^{2}\right)$.

The value of PPD (total) can then be calculated by using the mean radiant temperature from Eq. (8) substituted into the expression in Eq. (1) and Eq. (2). The value of PPD (surface temperature) can be calculated by using the mean radiant temperature from Eq. (7) substituted into the expression in Eq. (1) and Eq. (2), as well.

\section{Experimental Set Up and Uncertainty Analysis}

The experiment is performed in a test room to investigate the effect of glass window on a person who sits nearby in term of thermal comfort. The test room is located on the fourth floor of Hans Buntli building, Department of Mechanical Engineering, Faculty of Engineering, Chulalongkorn University. The test room is constructed as a double wall room with a 2 -in. fiber glass placed in between. The west wall, which is the wall exposing to the outside air, is constructed with aluminum cladding as the outside surface and a gypsum board as the inside surface with a 2 -in. fiber glass placed in between. The glass window with the size of 0.9 $\mathrm{x} 1.1 \mathrm{~m}$ is installed as the test window on the west wall. The layout and dimension of the test room is shown in Fig. 1. 


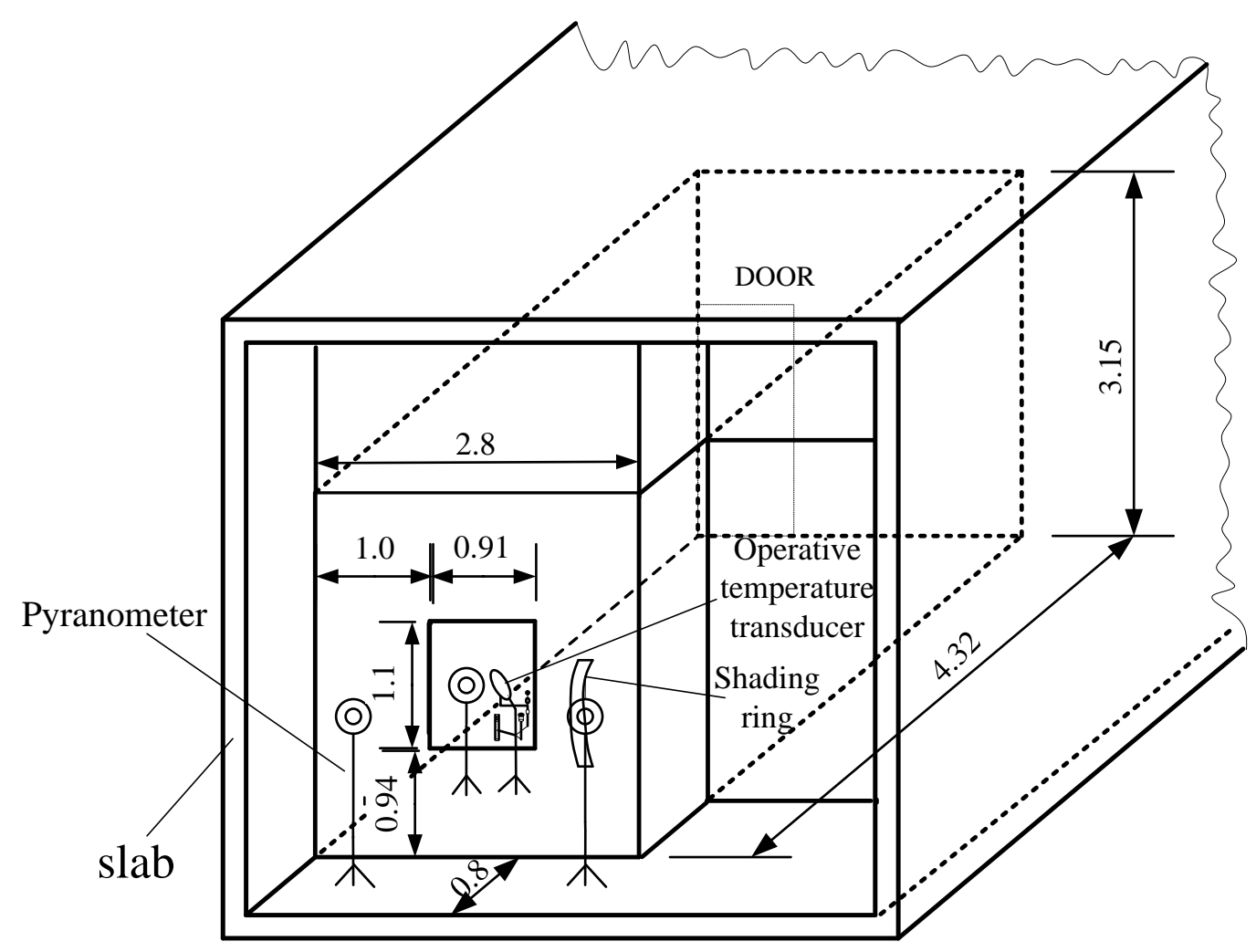

Fig. 1. The layout and dimension of the test room.

\subsection{Experiment Set Up}

Three pyranometers ((Kipp \& Zonen) model CM 6B, CMP 6) are used to measure the outside solar radiation and transmitted solar radiation. The shading ring is also used with a pyranometer to measure the diffuse solar radiation. Two pyranometers are installed outside the test room to measure the outside solar radiation incident on the vertical surface and another pyranometer is installed inside the test room to measure the transmitted solar radiation. Air temperature transducer (Innova, MM0034), air velocity transducer (Innova, MM0038) and air humidity transducer (Innova, MM0037) are used to measure the inside air temperature, air velocity and air humidity (in term of vapor partial pressure). The operative temperature transducer (Innova, MM0060) (which has an ellipsoid shape of $160 \mathrm{~mm}$ long and $54 \mathrm{~mm}$ in diameter) is also used to measure the operative temperature (temperature of an imaginary environment that transfers dry heat at the same rate as the actual environment) of a room. The operative temperature transducer is installed in the inclining position making 30 degree to the vertical direction to simulate a person in the sitting position. The data measured from the transducers are fed to the thermal comfort data logger (Innova 1221). The transducers are connected to the thermal comfort data logger by Innova's special modules (Comfort module (UA1276), Heat stress module (UA1277), Dry heat loss module (UA1278) and Analog interface module (UA1346)). The data from the transducers are processed by the software in the thermal comfort data logger to obtain the value of the thermal comfort indices. The surface temperature of the glass window and walls of the test room are measured by using thermocouple type J. The measured data from the pyranometers and thermocouples are stored by using NI (National Instrument) data logger. Figures 2 and 3 show the installation of the pyranometers and transducers. 


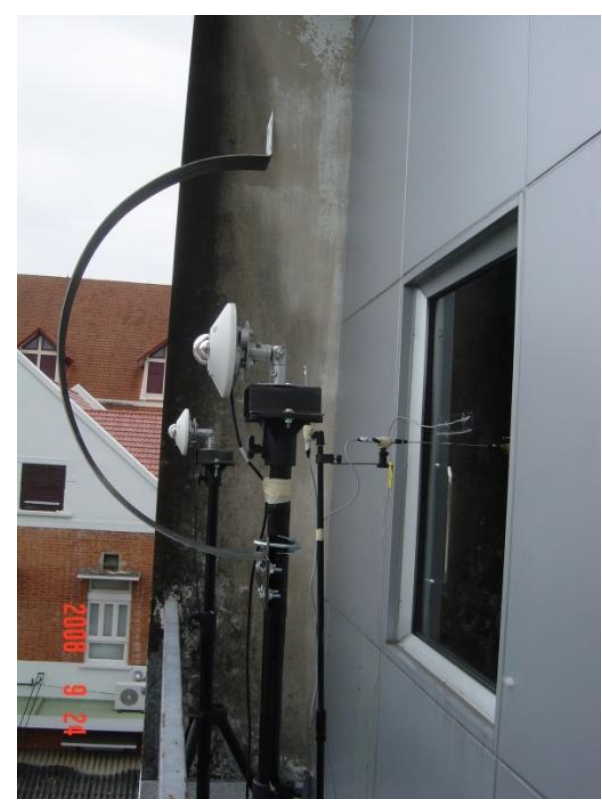

Fig. 2. The pyranometers and a shading ring.

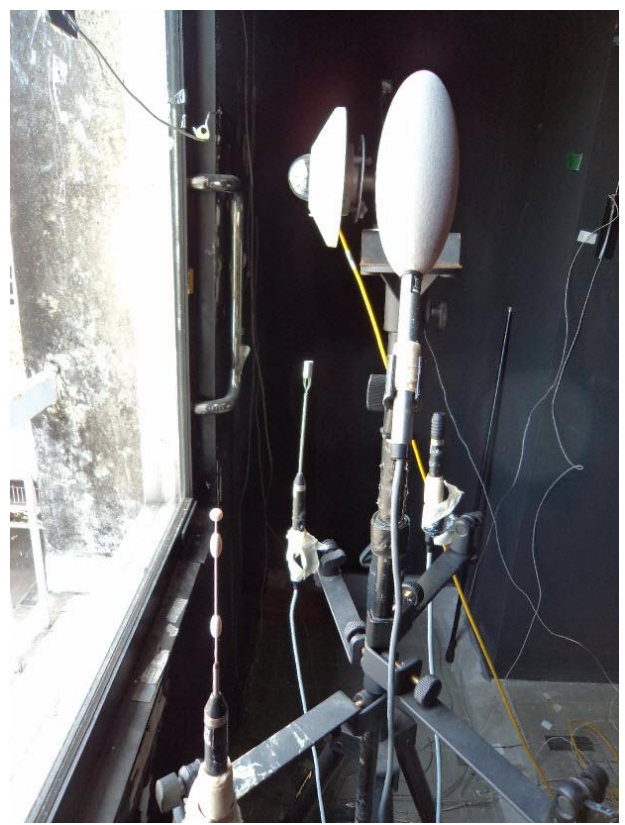

Fig. 3. Pyranometer used for measuring the transmitted solar radiation and transducers used for measuring the operative temperature and inside air properties.

In order to determine the thermal comfort condition in an enclosure, one of the important parameters needed to know is the mean radiant temperature. One way to obtain the value of the mean radiant temperature is to calculate by using the expression described in Eq. (8) which involved values of the temperature of all surfaces in the room and the values of the transmitted solar radiation in the room. Measuring all the parameters mentioned is very time consuming and even more time consuming is the calculation of the corresponding angle factors. The other way to obtain the mean radian temperature is to measure the operative temperature (the temperature that integrated the effect of the mean radiant temperature and air temperature [21]) by using special type of transducer (operative temperature transducer). In this study, the mean radiant temperature of the test room is also determined by using the value of the measured operative temperature. The relations that the thermal comfort data logger used to convert the value of the measured operative temperature into the mean radiant temperature are as the following [21] 


$$
\begin{gathered}
T_{\text {smrto }}=\left[\left(T_{o}+273\right)^{4}+\frac{h_{c g}}{\varepsilon_{p} \sigma}\left(T_{o}-T_{a}\right)\right]^{0.25}-273 \\
h_{c g}=\max \text { of } \begin{cases}18 \times v_{a}^{0.55} & \text { Forced convection } \\
3 \times\left(\left|T_{o}-T_{a}\right|\right)^{0.25} & \text { Free convection }\end{cases}
\end{gathered}
$$

where $\quad T_{\text {smrto }}=$ mean radiant temperature due to surface temperature and solar radiation evaluated from the value of the operative temperature, $\left({ }^{\circ} \mathrm{C}\right)$;

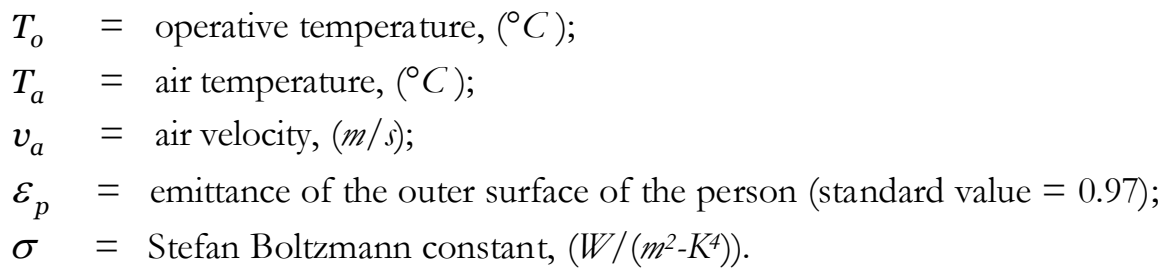

\subsection{Uncertainty Analysis}

In this study, the measured data are global solar radiation incident on the vertical surface, diffuse solar radiation incident on the vertical surface, transmitted global solar radiation, air temperature, air velocity, air humidity, operative temperature, wall surface temperatures and glass window surface temperatures. The predicted data are the mean radiant temperature due to surface temperature, mean radiant temperature due to solar radiation and surface temperature, PMV, PPD and transmitted solar radiation. There are also data that evaluated from the value of the operative temperature. The data are the mean radiant temperature, PMV and PPD which evaluated from the measured operative temperature. The uncertainty analysis is performed on the measured data, predicted data and data evaluated from the measured operative temperature.

For the solar radiation data, the sources of uncertainty include the accuracy of the sensor and the error due to the set up of the sensor. The total uncertainty of the measured data is calculated from the root sum square of all bias uncertainty related to the measurement. The sensor errors (CM 6B and CMP 6) as published by the manufacturer [22] are used to calculate the uncertainty due to the sensor errors. The error due to the set up the pyranometer (i.e. the orientation of the pyranometer relative to the glass window surface) is also estimated (no greater than $4^{\circ}$ in the vertical and horizontal plane) and used for calculating the uncertainty due to the set up. The error due to the set up of the shading ring is estimated to be $\pm 0.5 \%$ of the measured solar radiation. The total uncertainty of the measured data is estimated to be about $\pm 8.12 \%$ of the incident global solar radiation and $\pm 8.20 \%$ of the incident diffuse solar radiation. The total uncertainty of the transmitted solar radiation is also estimated to be about $\pm 8.12 \%$.

For the predicted data on the transmitted solar radiation (which is calculated from the expression shown in Eq. (12)) is dependent on two independent measured variables (incident global solar radiation and diffuse solar radiation). The uncertainty of the predicted solar radiation is estimated from the following expression:

$$
U_{I_{\text {tran }}}=\sqrt{\left(\frac{\partial I_{\text {tran }}}{\partial I_{\text {glob }}} U_{I_{\text {glob }}}\right)^{2}+\left(\frac{\partial I_{\text {tran }}}{\partial I_{\text {diff }}} U_{I_{\text {diff }}}\right)^{2}}
$$

where $U_{I_{\text {tran }}}$ is the total uncertainty of the predicted solar radiation that transmitted through the glass window, $\left(W / m^{2}\right)$;

$U_{I_{g l o b}}$ is the total uncertainty of the incident global solar radiation, $\left(\mathrm{W} / \mathrm{m}^{2}\right)$;

$U_{I_{\text {diff }}}$ is the total uncertainty of the incident diffuse solar radiation, $\left(\mathrm{W} / \mathrm{m}^{2}\right)$;

$I_{\text {tran }}$ is the predicted solar radiation that transmitted through the glass window (Eq. (12)), $\left(W / m^{2}\right)$;

$I_{\text {glob }}$ is the incident global solar radiation on the vertical surface, $\left(\mathrm{W} / \mathrm{m}^{2}\right)$;

$I_{\text {diff }}$ is the incident diffuse solar radiation on the vertical surface, $\left(\mathrm{W} / \mathrm{m}^{2}\right)$;

Therefore, the total uncertainty of the predicted solar radiation can be rewritten as 


$$
U_{I_{\text {tran }}}=\sqrt{\left(T(\theta) U_{I_{\text {glob }}}\right)^{2}+\left(\left[T_{\text {diff }}-T(\theta)\right] U_{I_{\text {diff }}}\right)^{2}}
$$

The total uncertainty of the predicted transmitted solar radiation in the unit of $\mathrm{W} / \mathrm{m}^{2}$ can be rewritten in percent as

$$
U_{I_{\text {tran\% }}}=\frac{U_{I_{\text {tran }}}}{I_{\text {tran }}} \times 100
$$

The average estimated uncertainty of the predicted data for the clear glass window is about $\pm 8.2 \%$ of the transmitted solar radiation. The average estimated uncertainty of the predicted data for the grey glass window is about $\pm 6.8 \%$ of the transmitted solar radiation.

The next parameter that needed to perform the uncertainty analysis is the mean radiant temperature due to surface temperature and solar radiation (Eq. (8)). The uncertainty of the predicted mean radiant temperature (no error due to the angle factors are considered) can be written as

$$
U_{T_{s m r t}}=\sqrt{\left(\frac{\partial T_{\text {smrt }}}{\partial t_{s 1}} U_{t_{s 1}}\right)^{2}+\ldots . .+\left(\frac{\partial T_{s m r t}}{\partial t_{s n}} U_{t_{s n}}\right)^{2}+\left(\frac{\partial T_{\text {smrt }}}{\partial I_{\text {glob }}} U_{I_{g l b b}}\right)^{2}+\left(\frac{\partial T_{\text {smrt }}}{\partial I_{\text {diff }}} U_{I_{\text {diff }}}\right)^{2}}
$$

where $U_{T_{s n n t}}$ is the total uncertainty of the predicted mean radiant temperature due to surface temperature and solar radiation, $\left({ }^{\circ} \mathrm{C}\right)$;

$U_{t_{s 1}}$ is the total uncertainty of the surface temperature of wall number $1,\left({ }^{\circ} \mathrm{C}\right)$;

$U_{t_{s n}}$ is the total uncertainty of the surface temperature of wall number $n,\left({ }^{\circ} \mathrm{C}\right)$;

$U_{I_{g l b b}}$ is the total uncertainty of the incident global solar radiation, $\left(\mathrm{W} / \mathrm{m}^{2}\right)$;

$U_{I_{\text {diff }}}$ is the total uncertainty of the incident diffuse solar radiation, $\left(\mathrm{W} / \mathrm{m}^{2}\right)$.

The total uncertainty of the predicted mean radiant temperature in the unit of ${ }^{\circ} \mathrm{C}$ can be rewritten in percent as

$$
U_{T_{\text {smrt } \%}}=\frac{U_{T_{\text {smrt }}}}{T_{\text {smrt }}} \times 100
$$

The uncertainty of the mean radiant temperature evaluated from the value of the operative temperature (Eq. (14)) can be written as

$$
U_{T_{\text {smro }}}=\sqrt{\left(\frac{\partial T_{\text {smrto }}}{\partial T_{o}} U_{T_{o}}\right)^{2}+\left(\frac{\partial T_{\text {smrto }}}{\partial T_{a}} U_{T_{a}}\right)^{2}+\left(\frac{\partial T_{\text {smrto }}}{\partial v_{a}} U_{v_{a}}\right)^{2}}
$$

where $U_{T_{\text {smrto }}}$ is the total uncertainty of the mean radiant temperature evaluated from the value of the operative temperature, $\left({ }^{\circ} \mathrm{C}\right)$;

$U_{T_{o}}$ is the total uncertainty of the operative temperature, $\left({ }^{\circ} \mathrm{C}\right)$;

$U_{T_{a}}$ is the total uncertainty of the air temperature, $\left({ }^{\circ} \mathrm{C}\right)$;

$U_{v_{a}}$ is the total uncertainty of the air velocity, $(\mathrm{m} / \mathrm{s})$.

The total uncertainty of each measured data from the transducers is obtained from the accuracy of the transducer published by the manufacturer [23] (neglected the error from the set up). The uncertainty of the surface temperature can be estimated from the error of the sensor. The estimated uncertainty of the surface temperature is $\pm 0.5^{\circ} \mathrm{C}$.

The total uncertainty of the mean radiant temperature evaluated from the value of operative temperature in the unit of ${ }^{\circ} \mathrm{C}$ can be rewritten in percent as

$$
U_{T_{\text {smrto\% }}}=\frac{U_{T_{\text {surto }}}}{T_{\text {smrto }}} \times 100
$$

The average estimated uncertainty of the predicted mean radiant temperature for the clear glass window is about $\pm 2.5 \%$ of the mean radiant temperature. The average estimated uncertainty of the predicted mean radiant temperature for the grey glass window is about $\pm 1.9 \%$ of the mean radiant temperature.

The average estimated uncertainty of the mean radiant temperature evaluated from the measured operative temperature for the clear glass window is about $\pm 3.5 \%$ of the mean radiant temperature. The 
average estimated uncertainty of the mean radiant temperature evaluated from the measured operative temperature for the grey glass window is about $\pm 3.3 \%$ of the mean radiant temperature.

The uncertainty of the PMV and PPD are also evaluated in the same way as the mean radiant temperature. The uncertainty of the PMV can be written as

$$
U_{P M V}=\sqrt{\left(\frac{\partial P M V}{\partial T_{\text {smrt }}} U_{T_{s m r t}}\right)^{2}+\left(\frac{\partial P M V}{\partial T_{a}} U_{T_{a}}\right)^{2}+\left(\frac{\partial P M V}{\partial v_{a r}} U_{v_{a r}}\right)^{2}+\left(\frac{\partial P M V}{\partial p_{a}} U_{p_{a}}\right)^{2}}
$$

where $U_{P M V}$ is the total uncertainty of the PMV;

$U_{T_{s m r t}}$ is the total uncertainty of the mean radiant temperature, $\left({ }^{\circ} \mathrm{C}\right)$;

$U_{T_{a}}$ is the total uncertainty of the air temperature, $\left({ }^{\circ} \mathrm{C}\right)$;

$U_{v_{a r}}$ is the total uncertainty of the relative air velocity, $(\mathrm{m} / \mathrm{s})$;

$U_{p_{a}}$ is the total uncertainty of the vapour partial pressure, $(\mathrm{Pa})$.

The uncertainty of the PPD can be written as

$$
U_{P P D}=\sqrt{\left(\frac{\partial P P D}{\partial P M V} U_{P M V}\right)^{2}}
$$

where $U_{P P D}$ is the total uncertainty of the PPD;

$U_{P M V}$ is the total uncertainty of the PMV.

The average estimated uncertainty of the predicted PMV for the clear glass window is about \pm 0.25 . The average estimated uncertainty of the predicted PMV for the grey glass window is about \pm 0.19 .

The average estimated uncertainty of the PMV evaluated from the measured operative temperature for the clear glass window is about \pm 0.3 . The average estimated uncertainty of the predicted PMV for the grey glass window is about \pm 0.24 .

The average estimated uncertainty of the predicted PPD for the clear glass window is about $\pm 2 \%$ (during the time of 5.00 to 14.00 and 18.00-19.00) and is about $\pm 10 \%$ (during the time of $14.00-18.00$ ). The average estimated uncertainty of the predicted PPD for the grey glass window is about $\pm 2 \%$ (during the time of 5.00 to 14.00 and 18.00-19.00) and is about $\pm 9 \%$ (during the time of 14.00-18.00).

The average estimated uncertainty of the PPD evaluated from the measured operative temperature for the clear glass window is about $\pm 2 \%$ (during the time of 5.00 to 14.00 and $18.00-19.00$ ) and is about $\pm 13 \%$ (during the time of 14.00-18.00). The average estimated uncertainty of the PPD evaluated from the measured operative temperature for the grey glass window is about $\pm 2 \%$ (during the time of 5.00 to 14.00 and 18.00-19.00) and is about $\pm 12 \%$ (during the time of $14.00-18.00$ ).

\section{Thermal Comfort Performance}

The effect of the glass window imposed on a person sitting near the glass window in term of thermal comfort is investigated by performing the experiment in the test room. Two types of commonly used glass window are chosen for the study. They are a $6 \mathrm{~mm}$ clear glass window and a $6 \mathrm{~mm}$ tinted glass window. The tinted glass window is the grey glass window. The optical properties of the glass windows are shown in Table 1. The operative temperature transducer is placed inside the test room at a distance of $200 \mathrm{~mm}$ away from the glass window surface. The operative temperature transducer is set at an inclined position (making $30^{\circ}$ respect to the vertical direction) to simulate the person in the sitting position (at $200 \mathrm{~mm}$ from the glass window) turning side way to the window. The metabolic rate of the person is chosen to be $1.2 \mathrm{Met}(\mathrm{M}=70$ $\left.W / m^{2}\right)$ ) corresponding to normal work when sitting in an office. The clothing insulation $\left(I_{c l}\right)$ is chosen to be $0.0775\left(m^{2}-K\right) / W(0.5 c l o)$. The mechanical efficiency of the person is set to be 0 . The inside air temperature is kept around $25{ }^{\circ} \mathrm{C}$ by using the direct expansion (DX) split type air conditioning unit. The experiment is performed and all measuring data are recorded. The recorded data are then evaluated and used in the mathematical model (described in section 2 and section 3) to study for the effect of the glass window on the human thermal comfort. 
Table 1. Glass optical properties.

\begin{tabular}{|c|c|c|c|c|c|c|}
\hline \multirow{2}{*}{ Description } & \multicolumn{2}{|c|}{ Visible } & \multicolumn{3}{|c|}{ Solar Eneroy } & \multirow{2}{*}{ Em } \\
\hline & $\operatorname{Trn}$ & Ref & Trn & Ref & $\overline{\mathrm{Ab}}$ & \\
\hline Clear glass & 0.89 & 0.08 & 0.8 & 0.08 & 0.12 & 0.84 \\
\hline Tinted glass & 0.14 & 0.05 & 0.3 & 0.05 & 0.65 & 0.84 \\
\hline
\end{tabular}

Note: $\operatorname{Trn}=$ transmittance; $\operatorname{Ref}=$ reflectance; $\mathrm{Ab}=$ absorptance; $\mathrm{Em}=$ emittance.

\subsection{Clear Glass Window}

The experiment was performed during the month of December in the year of 2011. Figures 4 and 5 show the measured values of the global solar radiation incident on the glass window, diffuse solar radiation incident on the glass window and transmitted solar radiation through the glass window varying with time for the clear glass window (accompany with the uncertainty bar). Since the test room is facing west, only the diffuse solar radiation can be measured in the morning. Figure 4 shows a very good agreement between the measured outside global solar radiation and measured diffuse solar radiation in the morning (time around 6.00 to 12.30). The direct solar radiation is incident on the glass window starting from around 12.30-13.00. The transmitted solar radiation has a similar pattern to the outside global solar radiation but having a smaller magnitude. Figure 5 shows the comparison between the measured transmitted solar radiation and the predicted transmitted solar radiation (calculated by using expression in Eq. (12)). The agreement between the measured data and the predicted data is quite good in the afternoon (14.30 to 18.00). There is some discrepancy between the measured and predicted data around the time of 9.00 to 14.30. The discrepancy around the time of 9.00 to 13.00 is contributed to the part of the diffuse solar radiation. While the largest discrepancy occurred during the time of 13.00 to 14.30 is contributed to the part of the direct solar radiation incident on the glass window. The possible explanation about this discrepancy is that during that period the measured incident solar radiation by the pyranometer (used to calculate the transmitted solar radiation) is different from the solar radiation that incident on the glass window surface. The outside pyranometer is installed on a tripod, therefore the sensor of the pyranometer is about $400 \mathrm{~mm}$ away from the glass window surface due to the distance from the tripod's leg to the center of the tripod. There is a horizontal slab of $800-\mathrm{mm}$ length protruding over the test room. There are also another two vertical slabs located on the north and south side of the test room (see Fig. 1). These slabs block certain amount of solar radiation that incident on the pyranometer sensor to reach the glass window surface. They block some diffuse solar radiation to reach the glass window surface in the morning and block a part of direct solar radiation around the time of 13.00 to 14.30 . After the time of 14.30 the effect of the shading from the slabs and the set back of the glass window surface from the pyranometer sensor is diminished as the sun is traveling toward the west direction and it is facing directly on the glass window surface. Therefore after the time of 14.30 the agreement between the predicted data and the measured data becomes quite good again.

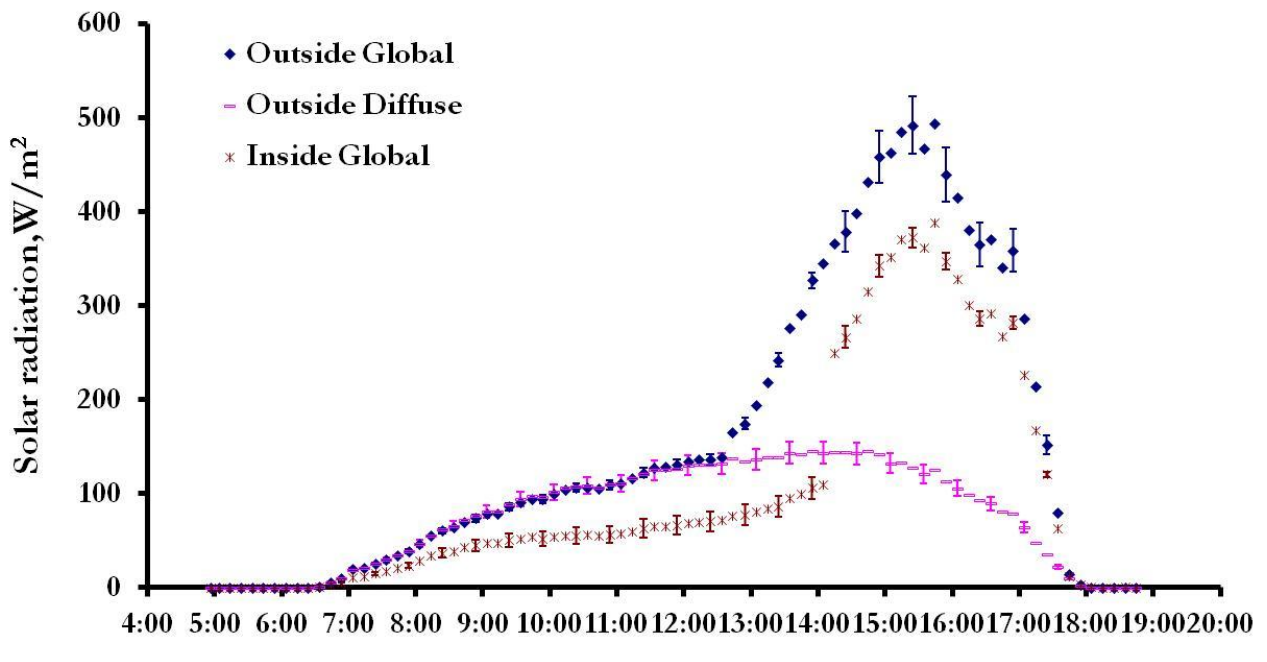

Time

Fig. 4. Incident solar radiation and transmitted solar radiation on the clear glass window. 


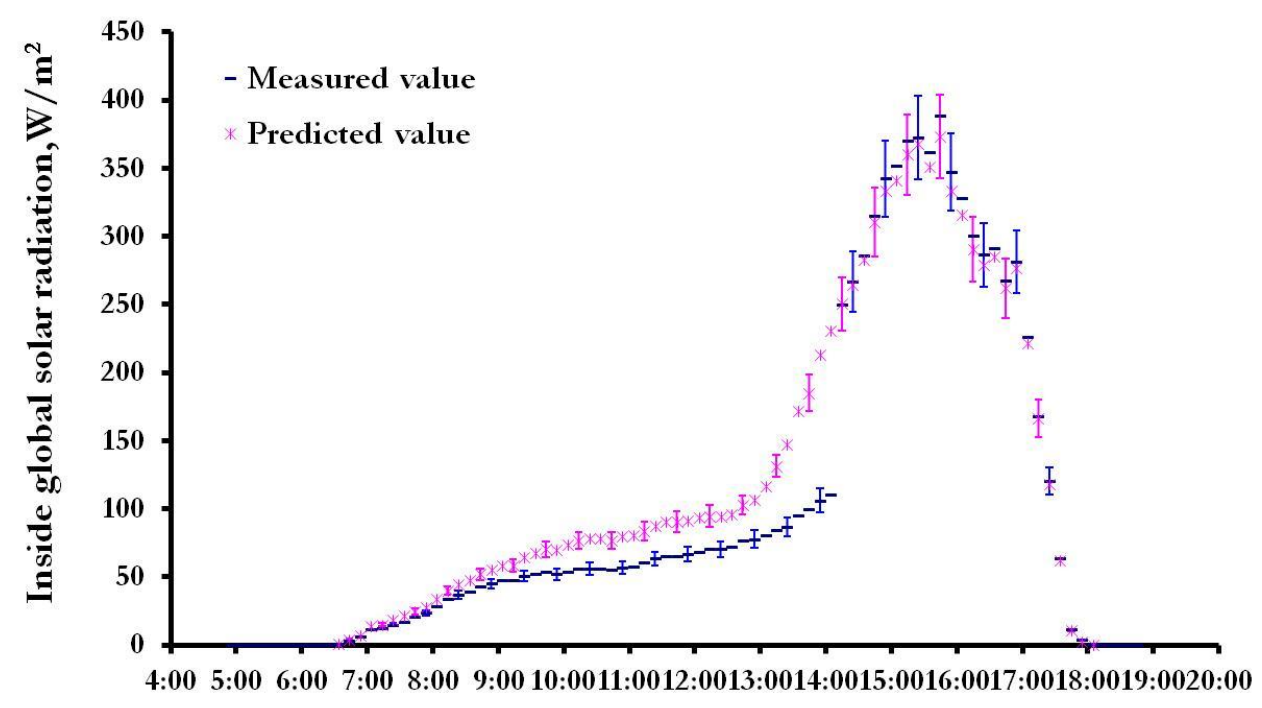

Time

Fig. 5. Measured and predicted values of the transmitted solar radiation through the clear glass window.

Figure 6 shows the variation of the outside air temperature, inside air temperature, glass window surface temperatures and operative temperature with time for the clear glass window. The air inside temperature is fluctuating around $22^{\circ} \mathrm{C}$ to $25^{\circ} \mathrm{C}$. The value of the inside glass surface temperature is quite close to the value of the outside glass surface temperature. The inside glass surface temperature is increasing from around $21^{\circ} \mathrm{C}$ in the morning to the maximum value of $32^{\circ} \mathrm{C}$ in the afternoon when the incident solar radiation on the glass window is at the maximum value. The operative temperature also has a similar pattern to the transmitted solar radiation. The operative temperature is increasing from $24^{\circ} \mathrm{C}$ in the morning to the maximum value of $32^{\circ} \mathrm{C}$ in the afternoon. Figures 7,8 , and 9 show the variation of the mean radiant temperature, PMV and PPD with time for the clear glass window. The mean radiant temperatures shown in Fig. 7 are the predicted mean radiant temperature (calculated from mathematical model that used the value of surface temperature and solar radiation) and the mean radiant temperature (evaluated from the value of the operative temperature). The value of the mean radiant temperature due to surface temperature is also shown in Fig. 7 to illustrate the effect of the surface temperature and the solar radiation on the mean radiant temperature. The curve of the mean radiant temperature evaluated from the operative temperature has the similar pattern to the measured transmitted solar radiation. The predicted mean radiant temperature (the mean radiant temperature due to surface temperature and solar radiation) has also the similar pattern to the predicted transmitted solar radiation shown in Fig. 5. The agreement between the predicted mean radiant temperature and the mean radiant temperature evaluated from the operative temperature is quite acceptable. They are well within the range of the estimated uncertainty. The discrepancy around the time of 9.00 to 13.00 and 13.00 to 14.30 comes from the same reason as already explained in the transmitted solar radiation. One can see that the mean radiant temperature is dependent on the transmitted solar radiation. The mean radiant temperature due to surface temperature is small compared to the mean radiant temperature which included the solar radiation effect for the clear glass window. The agreement between the predicted mean radiant temperature and the mean radiant temperature evaluated from the measured operative temperature gives the researcher more confident in using the mathematical model to predict the mean radiant temperature which included the solar radiation effect. The mean radiant temperature is increasing from $23^{\circ} \mathrm{C}$ in the morning to the maximum value of $39^{\circ} \mathrm{C}$ in the afternoon. The maximum value of the mean radiant temperature due to the surface temperature is at $27^{\circ} \mathrm{C}$ in the afternoon.

Figure 8 shows the variation of the PMV with time. The pattern of the PMV is similar to the pattern of the mean radiant temperature shown in Fig. 7. The agreement between the predicted data and the data evaluated from the operative temperature is quite good. They are well within the estimated uncertainty range. The PMV value is increased from around 0 in the morning to 2.2 at the time of 15.00 to 17.00 in the afternoon. The value of the PMV due to surface temperature is increased from around 0 in the morning to 
0.65 in the afternoon. The thermal discomfort comes from the solar radiation and surface temperature effect. For clear glass window, the thermal discomfort is primary due to the solar radiation effect when there is the direct solar radiation incident on the glass window. The PMV due to the surface temperature is quite low compared to the PMV due to the solar radiation, especially in the afternoon.

Figure 9 shows the variation of the other thermal comfort index, PPD, with time for the clear glass window. The pattern of the PPD is quite similar to the pattern of the PMV and the mean radiant temperature shown in Fig. 7 and Fig. 8, respectively. The predicted PPD has a similar pattern to the PPD evaluated from the value of measured operative temperature. The agreement between the two sets of data is well within the uncertainty range. The value of the PPD is increasing from around $5 \%$ early in the morning to around $90 \%$ at the time of 15.00 to 17.00 in the afternoon. The PPD due to surface temperature is also increasing from around $5 \%$ in the morning to around $14 \%$ in the afternoon.

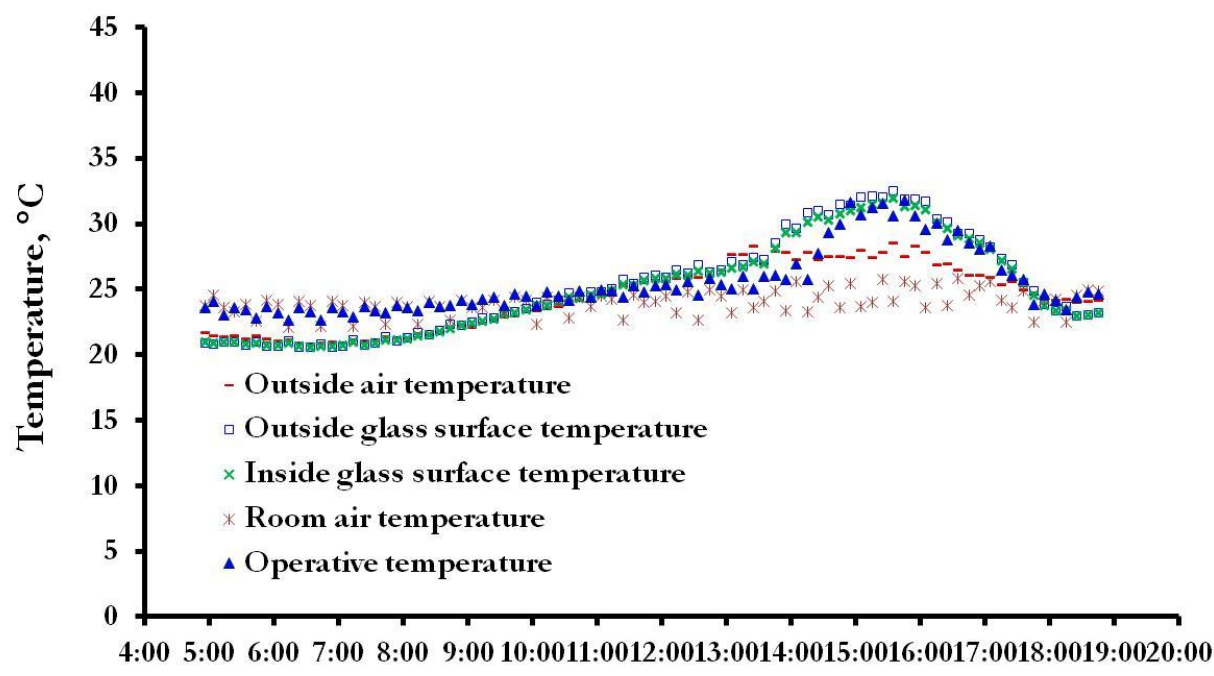

Time

Fig. 6. The variation of the outside air temperature, inside air temperature, glass window surface temperatures and operative temperature with time for the clear glass window.

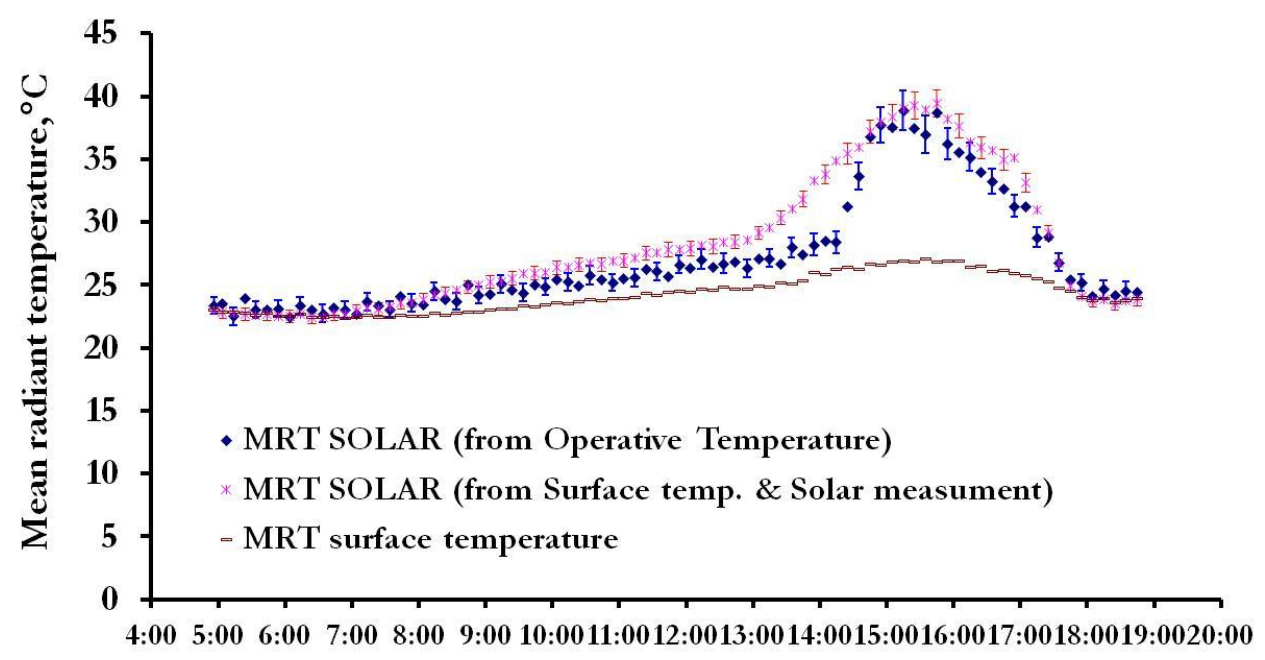

Time

Fig. 7. Comparison between the mean radiant temperature obtained from the mathematical model and evaluated from the operative temperature for the clear glass window. 


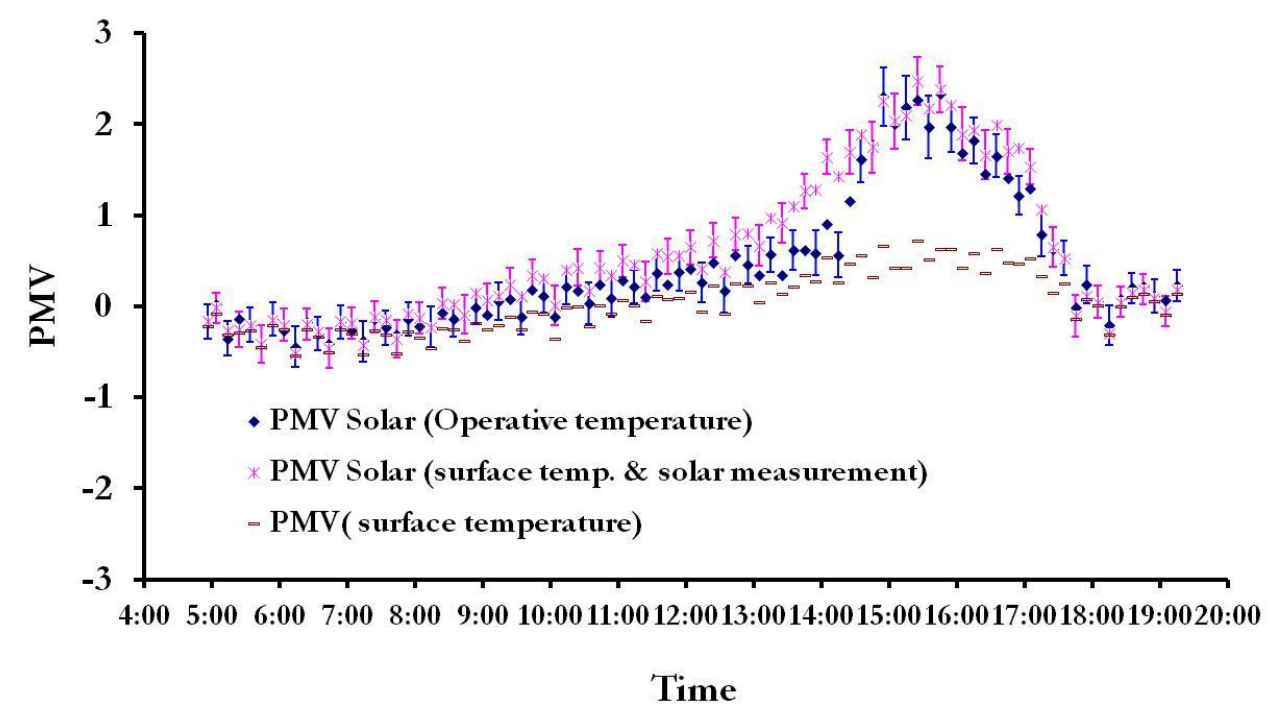

Fig. 8. Comparison between the PMV obtained from the mathematical model and evaluated from the operative temperature for the clear glass window.

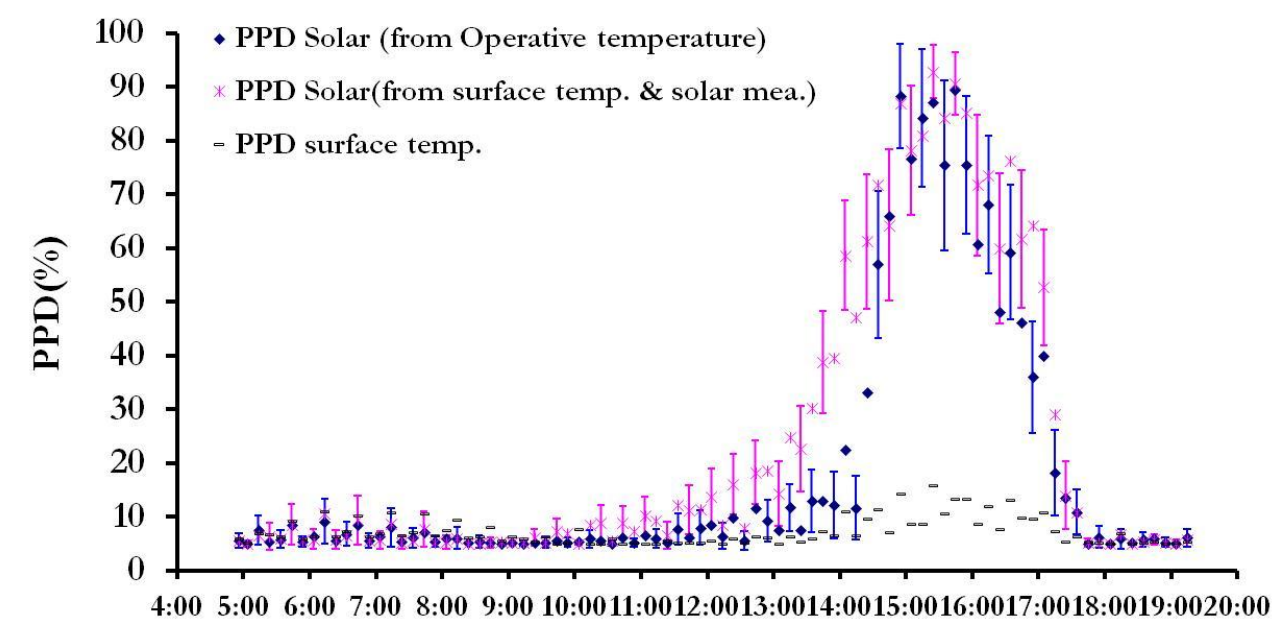

\section{Time}

Fig. 9. Comparison between the PPD obtained from the mathematical model and evaluated from the operative temperature for the clear glass window.

\subsection{Tinted Glass Window}

For the tinted glass window, the experiment was also performed during the month of December in the year of 2011. Figures 10 and 11 show the measured values of the incident global solar radiation on the glass window, incident diffuse solar radiation on the glass window and transmitted solar radiation through the glass window varying with time for the tinted glass window. Figure 10 shows a very good agreement between the measured outside global solar radiation and measured diffuse solar radiation in the morning (time around 6.00 to 12.30). The direct solar radiation is incident on the glass window starting from around 12.30 to 13.00 . The transmitted solar radiation has a similar pattern to the outside global solar radiation but having a smaller magnitude. Figure 11 shows the comparison between the measured transmitted solar radiation and the predicted transmitted solar radiation (calculated by using expression in Eq. (12)). The agreement between the measured data and the predicted data is quite good in the afternoon (14.30 to 18.00). There is some discrepancy between the measured and predicted data around the time of 13.00 to 14.30 . The discrepancy comes from the effect of the shading from the slabs and the set back of the glass window 
surface from the pyranometer sensor as mentioned in subsection 4.1. One thing should be noted is that the magnitude of the transmitted solar radiation through the tinted glass window is quite low compared to the value of the transmitted solar radiation through the clear glass window shown in Fig. 5. The reason of having a low value of transmitted solar radiation is due to the low transmittance of the tinted glass window compared to the clear glass window (Table. 1).

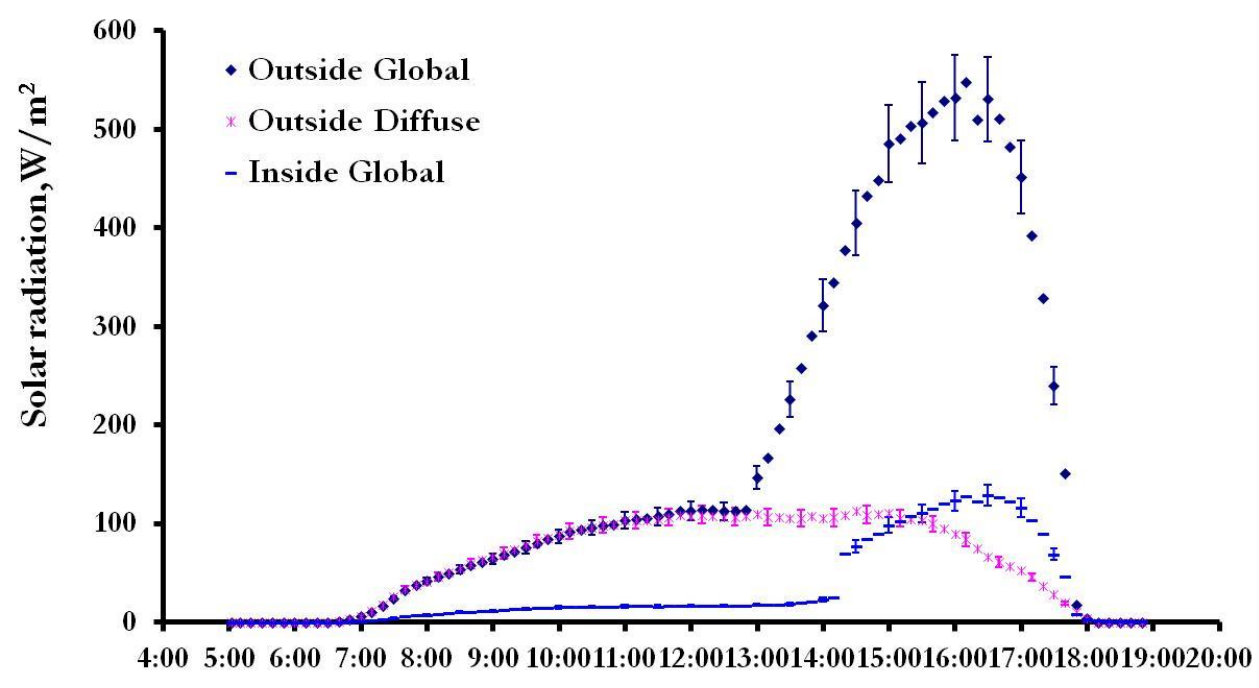

Time

Fig. 10. Incident solar radiation and transmitted solar radiation on the tinted glass window.

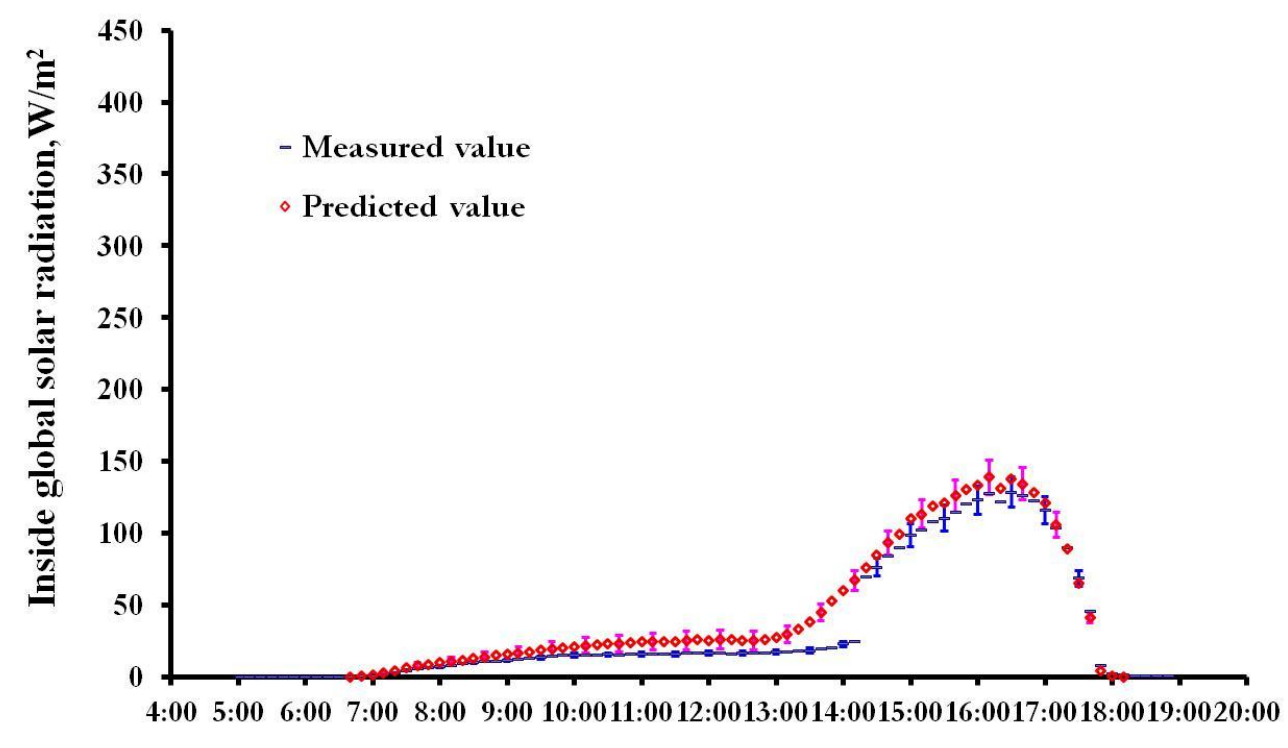

Time

Fig. 11. Measured and predicted values of the transmitted solar radiation through the tinted glass window.

Figure 12 shows the variation of the outside air temperature, inside air temperature, glass window surface temperatures and operative temperature with time for the tinted glass window. The air inside temperature is fluctuating around $25^{\circ} \mathrm{C}$. The value of the inside glass surface temperature is quite close to the value of the outside glass surface temperature. The inside glass surface temperature is increasing from around $25^{\circ} \mathrm{C}$ in the morning to the maximum value of $47^{\circ} \mathrm{C}$ in the afternoon when the incident solar radiation on the glass window is at the maximum value. The high value of the glass surface temperature is due to the high absorptance of the tinted glass window. The operative temperature also has the similar pattern to the transmitted solar radiation. The value of the operative temperature for the tinted glass 
window is increasing from $25^{\circ} \mathrm{C}$ in the morning to $30^{\circ} \mathrm{C}$ in the afternoon. One can see that for the glass window with high absorptance (low transmittance) the different between the glass surface temperature and the operative temperature is significant when there is solar radiation incident on the glass window. Figures 13, 14 and 15 show the variation of the mean radiant temperature, PMV and PPD with time for the tinted glass window, respectively. The mean radiant temperatures shown in the Fig. 13 are the predicted mean radiant temperature (calculated from mathematical model that used the value of surface temperature and solar radiation) and the mean radiant temperature evaluated from the value of the operative temperature. The values of the mean radiant temperature due to surface temperature are also shown in the Fig. 13 to illustrate the effect of the surface temperature and the solar radiation on the mean radiant temperature. The agreement between the mean radiant temperature evaluated from the operative temperature and the predicted mean radiant temperature is quite good. The predicted mean radiant has also the similar pattern to the predicted solar radiation that transmitted through the glass window as shown in Fig. 11. One can see that the mean radiant temperature is dependent on the transmitted solar radiation. The mean radiant temperature is increasing from $25^{\circ} \mathrm{C}$ in the morning to the maximum value of $38^{\circ} \mathrm{C}$ in the afternoon. The maximum value of the mean radiant temperature due to the surface temperature is at $33^{\circ} \mathrm{C}$ in the afternoon. The value of the mean radiant temperature due to surface temperature is rather high compared to the mean radiant temperature which included the solar radiation effect. The value of the mean radian temperature due to surface temperature for the tinted glass window is higher than the value of the mean radiant temperature due to surface temperature for the clear glass window.

Figure 14 shows the variation of the PMV with time. The pattern of the PMV is similar to the pattern of the mean radiant temperature shown in Fig. 13. The agreement between the predicted data and the data evaluated from the operative temperature is quite good. They are well within the estimated uncertainty range. The PMV value is increased from around 0 in the morning to 2 at the time of 15.00 to 17.00 in the afternoon. The PMV due to surface temperature is also increasing from around 0 in the morning to around 1.4 in the afternoon. The PMV due to the surface temperature is quite high compared to the PMV due to the solar radiation, especially in the afternoon.

Figure 15 shows the variation of the other thermal comfort index, PPD, with time for the tinted glass window. The pattern of the PPD is quite similar to the pattern of the PMV and the mean radiant temperature shown in Fig. 13 and Fig. 14, respectively. The predicted PPD has a similar pattern to the PPD evaluated from the value of measured operative temperature. The agreement between the two sets of data is well within the uncertainty range. The value of the PPD is increasing from around $8 \%$ early in the morning to around $76 \%$ at the time of 15.00 to 17.00 in the afternoon. The PPD due to surface temperature is also increasing to around $45 \%$ in the afternoon.

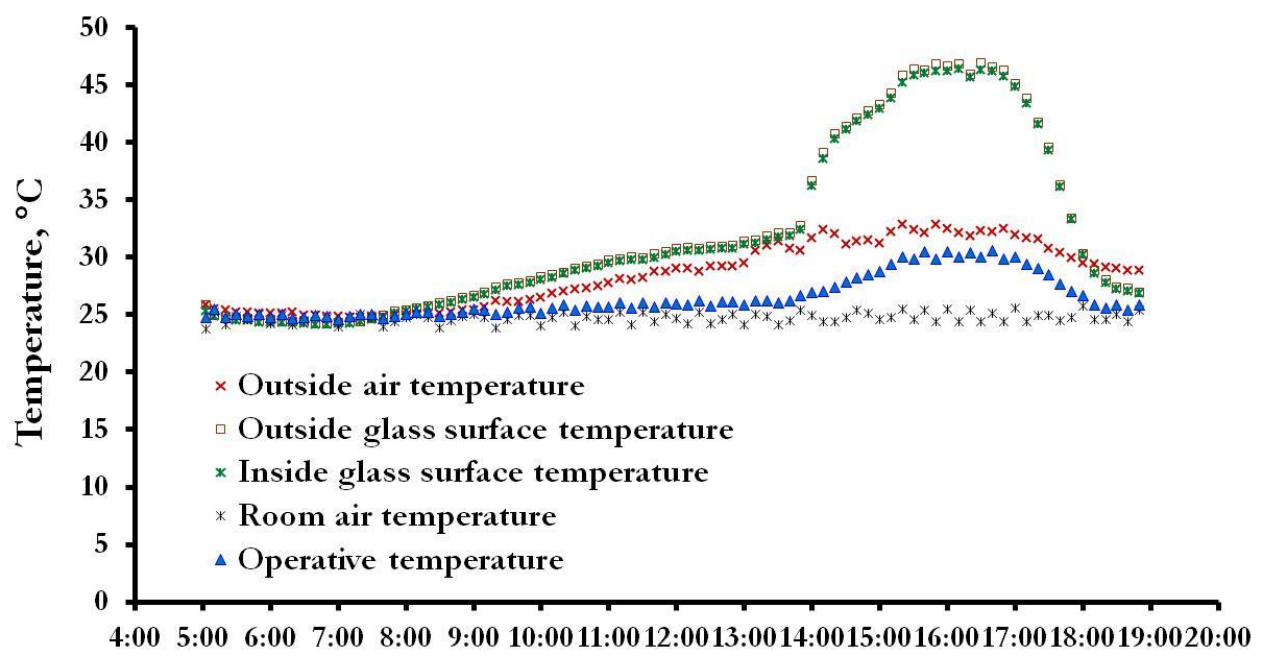

Time

Fig. 12. The variation of the outside air temperature, inside air temperature, glass window surface temperature and operative temperature with time for the tinted glass window. 


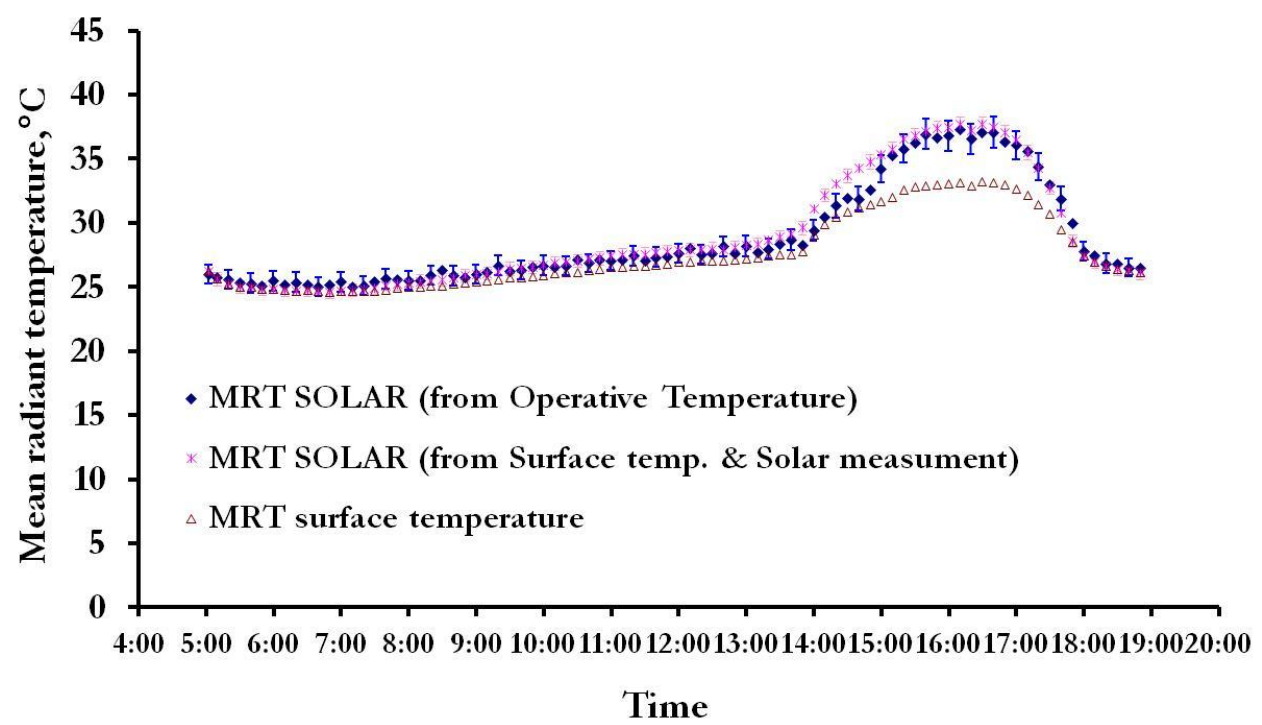

Fig. 13. Comparison between the mean radiant temperature obtained from the mathematical model and evaluated from the operative temperature for the tinted glass window.

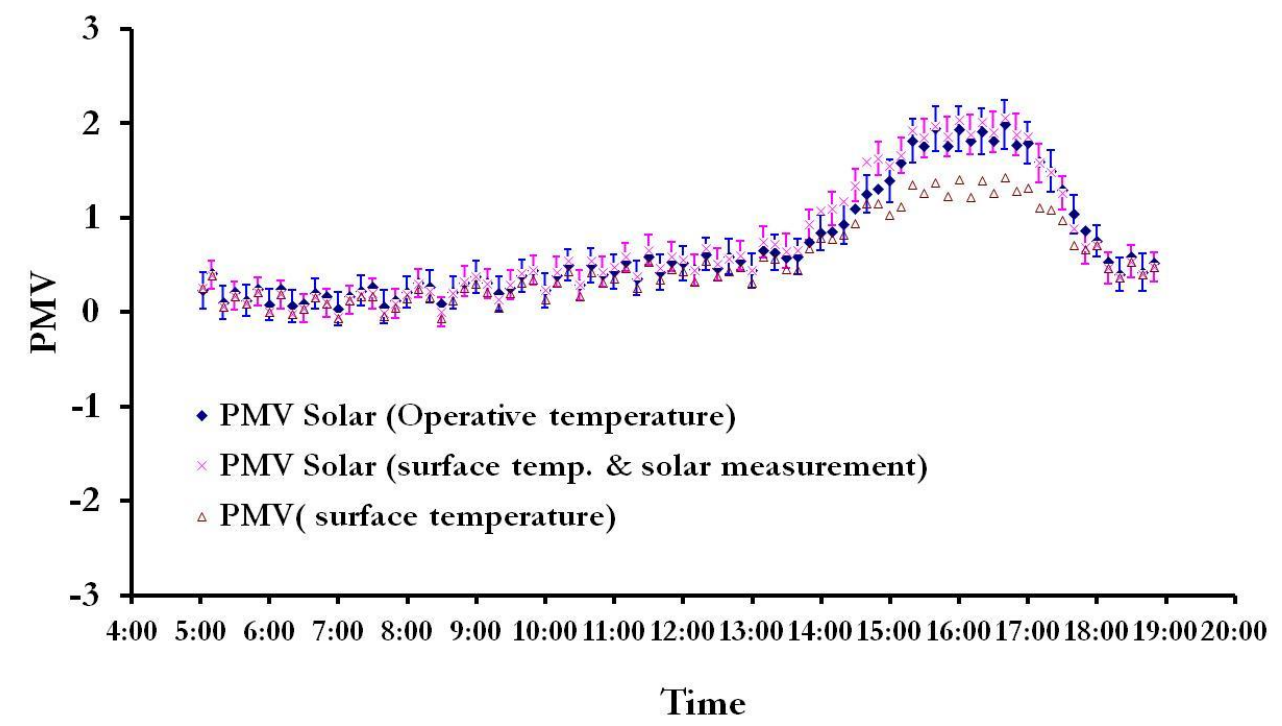

Fig. 14. Comparison between the PMV obtained from the mathematical model and evaluated from the operative temperature for the tinted glass window. 


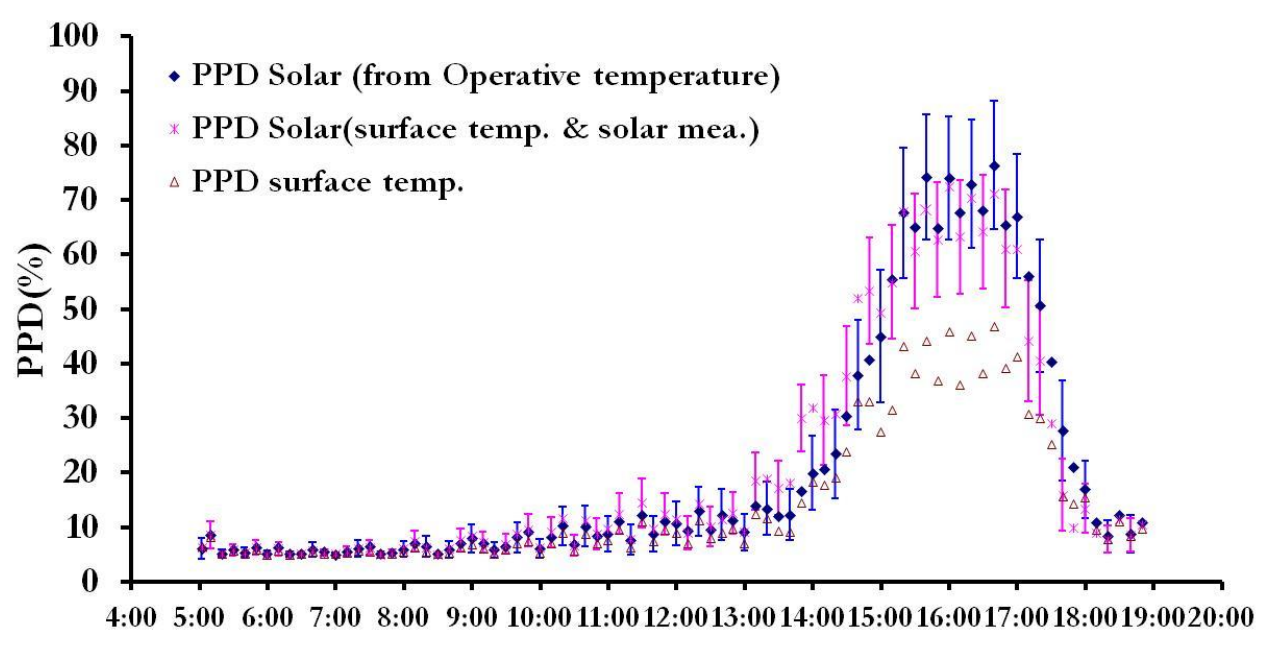

Time

Fig. 15. Comparison between the PPD obtained from the mathematical model and evaluated from the operative temperature for the tinted glass window.

From the study, it can be concluded that the mathematical model for calculating the mean radiant temperature that accounted for the effect of the surface temperature and solar radiation is accurate enough to use for predicting the thermal comfort of the enclosure having the glass window installed. The thermal comfort index, PPD, is directly dependent on the transmitted solar radiation and the mean radiant temperature. The time that no direct solar radiation passing through the glass window the thermal discomfort is mainly come from the effect of surface temperature. The discomfort from the solar radiation is dominated when the room (which has a high transmittance glass window installed) has high transmitted solar radiation. The discomfort from the surface temperature is dominated when the room (which has a high absorptance (low transmittance) glass window installed) has a high glass window surface temperature. It is also worthwhile to take a closer look at the value of the PPD for the clear glass window (Fig. 9) and the value of the PPD for the tinted glass window (Fig. 15). Though the tinted glass window can reduce a large amount of the heat gain due to solar radiation (in the shortwave part) compared to the clear glass window (by compared the transmitted solar radiation between the clear glass window and tinted glass window) the effect of thermal discomfort is still high. The reduction of the transmitted solar radiation (compared the maximum value of the transmitted solar radiation between the tinted glass window and the clear glass window $\left(135 \mathrm{~W} / \mathrm{m}^{2}\right.$ compared to $\left.\left.398 \mathrm{~W} / \mathrm{m}^{2}\right)\right)$ is about $76 \%$. While the maximum value of PPD is around $90 \%$ for the clear glass window and around $76 \%$ for the tinted glass window. The thermal comfort index is reduced only $14 \%$. Reducing the solar radiation transmitted through the room by using the low transmittance glass window may not be a good solution to reduce the energy usage in building when the effect on human thermal comfort is considered.

\section{Conclusion}

The effect of the glass window on the thermal comfort of a person sitting near the glass window is investigated by performing the experiment in a test room. The important parameter for the thermal comfort condition is the mean radiant temperature. The mean radiant temperature can be divided into the mean radiant temperature that accounted for the effect of the surface temperature and solar radiation and the mean radiant temperature that only accounted for the surface temperature. The accuracy of the mathematical model used for predicting the mean radiant temperature for the enclosure of a room with a glass window installed is verified by comparing the predicted values with the values evaluated from the measured operative temperature. The comparison shows a good agreement between the predicted values and the values evaluated from the measured operative temperature. It is found that the mean radiant temperature, the PMV and the PPD are all dependent on the transmitted solar radiation and the surface temperature of the glass window. Higher value of the mean radiant temperature yields higher value of the PMV and the PPD. The room with a clear glass window (which has high transmittance) installed will have 
high transmitted solar radiation compared to the room with a tinted glass window (which has low transmittance) when there is the direct solar radiation incident on the glass window. The room with the clear glass window installed has high thermal discomfort condition mainly from the solar radiation. The amount of the thermal discomfort is directly varied with the amount of the transmitted solar radiation. For a high transmittance glass window, the thermal discomfort due to solar radiation is greater than the thermal discomfort due to surface temperature. For a low transmittance (high absorptance) glass window, the thermal discomfort due to surface temperature becomes important when compared to the thermal discomfort in the part of solar radiation. With the confidence in the mathematical model that used to predict the human thermal comfort condition under the effect of solar radiation gained from this study, the variation of the other important parameters (such as the metabolic rate, the clothing insulation and the distance from the glass window, etc) on the thermal comfort condition are another subjects that worth to study in the future work. The effect of the other high performance glazing types (i.e. low-e double glazing, selective glazing, reflective glazing, etc which are now commercially available) on the human thermal comfort condition should also be another subjects that worth to study in the future work.

\section{Acknowledgements}

The authors are grateful for the financial support from the National Metal and Materials Technology Center, National Science and Technology Development Agency.

\section{References}

[1] Moderate Thermal Environments-Determination of the PMV and PPD Indices and Specification Of The Conditions For Thermal Comfort, ISO 7730, 1995.

[2] Thermal Environmental Conditions for Human Occupancy, ANSI/ASHRAE Standard 55-1992, 1992.

[3] P. O. Fanger, Thermal Comfort Analysis and Applications in Environmental Engineering. New York: McGrawHill, 1970.

[4] G. Rizzo, G. Franzitta, and G. Cannistraro, "Algorithms for the calculation of mean projected area factors of seated and standing persons," Energy and Buildings, vol. 17, no. 3, pp. 221-230, 1991.

[5] A. K. Athienitis and F. Haghighat, "A Study of the effects of solar radiation on the indoor environment," ASHRAE Transactions, vol. 98, no. 1, pp. 257-261, 1992.

[6] G. Cannistraro, G. Franzitta, C. Giaconia, and G. Rizzo, "Algorithms for the calculation of the view factors between human body and rectangular surfaces in parallelepiped environments," Energy and Buildings, vol. 19, no. 1, pp. 51-60, 1992.

[7] M. La Gennusa, A. Nucara, G. Rizzo, and G. Scaccianoce, "The calculation of the mean radiant temperature of a subject exposed to the solar radiation-a generalised algorithm," Building and Environment, vol. 40, no. 3, pp. 367-375, 2005.

[8] R. Sullivan, "Thermal comfort in the LRI study," in "International Memorandum/Report, Window and Daylighting Group,” Lawrence Berkeley National Laboratory, CA, USA, 1986.

[9] P. Lyons, D. Arasteh, and C. Huizenga, "Window performance for human thermal comfort," ASHRAE Transaction, vol. 106, no. 1, pp. 594-602, 2000.

[10] S. Chaiyapinunt, B. Phueakpongsuriya, K. Mongkornsaksit, and N. Khomporn, "Performance rating of glass windows and glass windows with films in aspect of thermal comfort and heat transmission," Energy and Buildings, vol. 37, pp. 725-738, 2005.

[11] M. La Gennusa, A. Nucara, M. Pietrafesa, and G. Rizzo, "A model for managing and evaluating solar radiation for indoor thermal comfort," Solar Energy, vol. 81, no. 5, pp. 594-606, 2007.

[12] A. Ibrahim, K. Omer, and Y. Abdulvahap, "Effects of radiant temperature on thermal comfort," Building and Environment, vol. 42, no. 9, pp. 3210-3220, 2007.

[13] M. C. Singh, S. N. Garg, and R. Jha, "Different glazing systems and their impact on human thermal comfort-Indian scenario," Building and Environment, vol. 43, no. 10, pp. 1596-1602, 2008.

[14] M. Y. Chan, and C. W. Mak, "Thermal comfort levels in a room with solar radiation," Indoor and Built Environment, vol. 17, no. 6, pp. 516-524, 2008.

[15] S. Chaiyapinunt and N. Khamporn, "Selecting glass window with film for buildings in a hot climate," Engineering Journal, vol. 13, no. 1, pp. 29-42, 2009. 
[16] H. K. Dong, H. M. Paek, H. C. Dong, Y. S. Seung, and S. Y. Myoung, " Effect of MRT variation on the energy consumption in a PMV-controlled office," Building and Environment, vol. 45, no. 9, pp. 1914-1922, 2010.

[17] R. L. Hwang and S. Y. Shu, "Building envelope regulations on thermal comfort in glass facade buildings and energy-saving potential for PMV-based comfort control, " Building and Environment, vol. 46, no. 4, pp. 824-834, 2011.

[18] R. A. Francesca, D. Marco, I. P. Boris, and R. Giuseppe, "The role of measurement accuracy on the thermal environment assessment by means of PMV index," Building and Environment, vol. 46, no. 7, pp. 1361-1369, 2011.

[19] M. Dell'Isola, A. Frattolillo, B. I. Palella, and G. Riccio, "Influence of measurement uncertainties on the thermal environment assessment," International Journal of Thermophysics, vol. 33, no. 8-9, pp. 16161632, 2012.

[20] E. U. Finlayson, D. K. Arasteh, C. Huizenga, M. D. Rubin, and M. S. Reilly, "Window 4.0 Documentation of Calculation Procedures," Lawrence Berkeley Laboratory, Rep. 33943, August 1993.

[21] Innova Air Tech Instruments, Thermal Comfort, Energivej 30, DK-2750, Denmark, BG 2002-12.

[22] Kipp \& Zonen. [Online]. Available: http://www.kippzonen.com/?productgroup/331/ Pyranometers.aspx, [Accessed: 21 May 2012].

[23] LumaSenses Techologies. (2013) Thermal comfort datalogger Innova-1221 [Online]. Available: http://www.lumasenseinc.com/EN/products/gas-monitoring/thermal-comfort/innova-1221/ [Accessed: 25 January 2013]. 
